\title{
CausaÇão E Física Clássica: Existe Possibilidade de Conciliação?
}

\author{
Túlio Roberto Xavier de Aguiar \\ Universidade Federal de Minas Gerais
}

\begin{abstract}
In this work, I analyze our concept of cause in the face of criticism of Bertrand Russell in his article "On the Notion of Cause". For Russell, there is an estrangement between the notion of cause and mature science of physics. The word cause (and its correlates) would not be used in physics, thus eliminating the main justification of philosophy for his job - the foundation of science. Thus, the various causal notions and the principle of causality should be abandoned by philosophers as something outdated. The aim of this study is to assess the extent to which our notion of cause, with its asymmetric nature, can be explained by physics and investigate the question of the existence of causes in our world.
\end{abstract}

Keywords: Laws; cause; asymmetry; isolated systems; Russell.

\section{Introdução}

Os últimos 40 anos foram férteis na produção de várias teorias da causação: contrafactual, agencial, física, dentre outras. Problemas importantes como o de distinguir uma relação causal da relação entre co-efeitos, da explicação do aspecto assimétrico da causação e da preempção foram atacados, produzindo uma melhor compreensão das noções causais. Nos últimos 10 anos, o debate infletiu para a questão da compatibilidade entre a nossa noção de causa e o conteúdo das teorias da física fundamental. Há dois grandes problemas nesta conexão: 1) a questão de se o nosso conceito de causação, com todas as suas notas características, pode ser explicado pela física; 2) o problema metodológico de se e como algum conceito de causação pode ser útil para compreender a nossa física. Trataremos do primeiro problema e suas ramificações.

$\mathrm{O}$ mais conhecido e radical desafio à utilidade das noções causais para a física e também para a filosofia foi lançado por Russell em seu On The Notion of Cause, de 1913. Segundo Russell, há uma incompatibilidade entre a noção de causa e a ciência da física. A palavra causa não seria utilizada nas teorias fundamentais de uma ciência desenvolvida como a física, tornando assim a noção de causa epistemologicamente ociosa e ontologicamente vácua. Em uma espirituosa passagem, Russell diz:

Todos os filósofos, de todas as escolas, imaginam que causação é um dos axiomas ou postulados fundamentais da ciência, ainda, estranhamente o bastante, nas ciências avançadas, tais como a astronomia gravitacional, a

Principia 16(3): 353-364 (2012).

Published by NEL — Epistemology and Logic Research Group, Federal University of Santa Catarina (UFSC), Brazil. 
palavra "causa" nunca ocorre. [...] Parece-me que a Filosofia não deveria assumir tais funções legislativas, e que a razão pela qual a física tem cessado de procurar por causas é que, de fato, não existem tais coisas. A lei da causalidade, eu acredito, como muitas outras coisas toleradas em filosofia, é uma relíquia de uma era ultrapassada, sobrevivendo, de forma semelhante à monarquia, apenas por que se supõe erradamente que ela não faz nenhum mal (Russell 1913, p.180).

Seguindo Hitchcock, podemos notar que esta passagem (e o texto de Russell em geral) pode ser reconstruída como abarcando quatro diferentes pontos: 1) a noção de causa é incoerente; 2) a palavra "causa" tem associações enganadoras; 3) não existem causas; 4) a lei de causalidade é obsoleta e enganadora (Hitchcok 2007, p.46). As quatro proposições não são equivalentes e suas relações lógicas são complexas. Notar, especialmente, que 3 e 4 não implicam separadamente, e nem conjuntamente, a proposição 1 . O princípio de causalidade, ainda importante nos dias de Russell, não encontra eco na literatura recente, havendo certo consenso sobre a sua pouca utilidade para a fundamentação da ciência. Do ponto de vista contemporâneo, devemos lidar com 2 como um passo preliminar para tratar das questões mais substanciais 1 e 3. Neste artigo, trataremos destas duas últimas questões.

Para Russell, a física substituiu a noção filosófica (e também ordinária) de causa, com conotações antropomórficas, pela noção cientificamente respeitável de dependência funcional. Assim, propriedades que atribuímos à relação causal como localidade e assimetria não teriam lugar em uma descrição física do mundo. Posição contrária é assumida por Nancy Cartwright que argumenta no sentido de mostrar que a assimetria das relações causais é fundamental para dar inteligibilidade às chamadas "estratégias efetivas": nós podemos controlar o efeito através de sua causa, mas não podemos fazer o contrário. As estratégias efetivas, que nos permitem intervir no mundo natural e humano, são parte integral não só do conceito ordinário de causação, mas também desempenham um papel fundamental nas ciências aplicadas, tais como medicina e engenharia. Sobre esta situação, Hartry Field diz que "o problema de reconciliar a opinião de Cartwright sobre a necessidade da causação em uma teoria das estratégias efetivas com a visão de Russell acerca da função limitada da causação na física [...] é provavelmente o problema central na metafísica da causação" (Field 2003, p.12).

Uma das principais dificuldades é explicar o caráter assimétrico que faz parte do nosso conceito de causação. Se as leis da física são simétricas no tempo, como explicar a relevância para nós da causação? E qual seria a fonte da assimetria dessa relação?

O objetivo desse trabalho é examinar em que medida é possível conciliar a noção plena de causação do senso comum e das ciências aplicadas com a física fundamental e avaliar a questão da existência das causas.

Principia 16(3): 353-364 (2012). 


\section{A crítica de Russell}

Três pontos podem resumir a crítica de Russell no que tange ao estranhamento noção de causa dos filósofos e a física. As relações causais são assimétricas, locais e as causas consideradas suficientes para seus efeitos. Começando pela suficiência, o ponto de Russell é que os eventos que consideramos causas são grosseiramente descritos como "riscar um fósforo" ou "colocar uma moeda em maquina automática". Se nós especificarmos demais um evento, como, por exemplo, "riscar um fósforo com a força $x$ e inclinação $y$ ”, ele acabará sendo único e não entrará em qualquer repetição. Um ponto conexo é que entre a causa e o seu efeito, quando grosseiramente descritos, algum tempo deve decorrer e, neste intervalo, vários acontecimentos podem frustrar a ocorrência do efeito. Em ambas as situações, o fato de descrevermos os eventos grosseiramente e de que tal descrição envolve algo muito menor do que a especificação de um estado físico completo leva a impossibilidade da aplicação plena do princípio "mesma causa, mesmo efeito". Para Russell, isto inviabilizaria certa concepção da causalidade proveniente da tradição filosófica. A maneira como descrevemos as causas impede que elas sejam suficientes para seus efeitos. Ou, tomando a contrapositiva, se as causas são suficientes para seus efeitos, elas não são os eventos grosseiramente descritos que estamos acostumados a pensar.

Quanto à assimetria das relações causais, Russell pensa que isto é uma ilusão criada pela analogia com a volição humana. Um ato da vontade compeliria a sua realização e não o contrário. De forma menos antropomórfica, as causas determinam os seus efeitos, mas os efeitos não determinam as suas causas. Russell considera este tipo de determinação ilusória e, na medida em que estamos tratando das leis da física, a simetria é a regra. Ele diz:

$\mathrm{A}^{1}$ lei não faz qualquer diferença entre passado e futuro: o futuro "determina" o passado exatamente no mesmo sentido em que o passado "determina" o futuro. A palavra "determina", aqui, tem um significado puramente lógico: certo número de variáveis "determina" outra variável se esta é uma função daquelas (Russell 1913, p.195).

Se a física utiliza dependências funcionais, então qualquer variável pode ser isolada e vista como sendo determinada pelas outras. Em suma, não há qualquer sentido não-antropomórfico ${ }^{2}$ da noção de determinação que privilegie certa direção temporal.

Em uma passagem consideravelmente menor, Russell critica a máxima de que "uma causa só pode operar onde ela está" como sendo destituída de fundamento e inspirada pelo pensamento de que causas "operam" em algum sentido obscuramente relacionado à volição. Isso explicaria a dificuldade da aceitação da ação à distância, por exemplo, na teoria gravitacional de Newton. 
Apesar do que foi dito acima, Russell admite que, no cotidiano e na infância da ciência, pode ser útil recorrer a certas seqüências regulares que constituem a base das nossas inferências causais. Tais regularidades, entretanto, só podem balizar as nossas práticas inferenciais se assumirmos que ocorrências em certa região do espaço seriam aproximadamente as mesmas quaisquer que fossem as diferenças em regiões remotas do espaço. O exemplo do próprio autor é o do movimento dos planetas no sistema solar. Este movimento seria aproximadamente o mesmo qualquer que fosse a distribuição das estrelas distantes. O sistema solar constitui o que Russell chama de sistema praticamente isolado. Em uma passagem muito fértil especulativamente, ele diz:

Se a gravitação variasse diretamente com a distância, de forma que as estrelas mais distantes fizessem a maior diferença para o movimento dos planetas, o mundo poderia ser tão regular e tão sujeito a leis matemáticas como ele de fato é, mas nós poderíamos nunca descobrir tal fato (Russell 1913, p.196).

Na experiência de pensamento proposta por nosso filósofo, a gravitação seria uma força cuja intensidade aumentaria com a distância, diferentemente do que ocorre no mundo atual. Assim, as estrelas distantes teriam uma influência grande sobre os planetas, complicando enormemente a descoberta de regularidades dentro do sistema solar. Nesse caso, nós não poderíamos tratar o sistema solar como um sistema praticamente isolado do resto do universo. Não poderíamos fazer asserções causais simples do tipo "as estrelas distantes causam o movimento da Terra", nem, obviamente, "o Sol causa o movimento da Terra". ${ }^{3}$ Russell reconhece a importância dos sistemas isolados para descoberta de leis científicas, negando, entretanto, que eles tenham qualquer importância na ciência acabada. Para esta, não são importantes generalizações que ligam eventos grosseiramente descritos, ${ }^{4}$ mas dependências funcionais entre variáveis que descrevem precisamente estados de um sistema e sua evolução. Outro ponto de Russell, no artigo, se dirige contra o caráter apriorístico do princípio de causalidade. O fato de que um sistema é praticamente isolado só pode ser conhecido empiricamente, constatando que certas regularidades podem ser descobertas e descritas fazendo referência apenas ao próprio sistema. Apenas nestes sistemas, onde descobrimos empiricamente quais simplificações podemos fazer, a máxima "mesma causa, mesmo efeito" pode ser útil.

\section{Causação no senso comum e nas ciências aplicadas}

Tentemos uma caracterização geral das relações causais como utilizadas pelo senso comum e pelas ciências aplicadas. Em primeiro lugar, e estreitamente relacionadas com as estratégias efetivas descritas por Cartwright, estas relações são assimétricas:

Principia 16(3): 353-364 (2012). 
se $a$ causa $b$, não é o caso que $b$ cause $a$. Em segundo lugar e contra uma confusa tradição filosófica, causas não se prestam a constituir condições suficientes. Nem o homem comum nem o médico ou o engenheiro pensam que um dado efeito se seguirá, em qualquer circunstância, à sua causa. Ao tomar uma aspirina, não penso que a minha dor de cabeça passará quaisquer que sejam as circunstâncias. Por exemplo, se estiver sob alguma fonte severa de estresse durante o período de ação do medicamento, não esperaria a remissão da dor. Mesmo uma forte explosão não levaria invariavelmente a uma ruptura de uma vidraça na região próxima a explosão, pois sempre podemos pensar em alguma forma de proteger a vidraça da força da explosão. Uma causa pode ser sempre, por assim dizer, escudada. Assim, se a relação causal pudesse ser representada por algum tipo de condicional, não valeria a regra do fortalecimento do antecedente.

Pensar em causas como condições suficientes é pensar em algo muito distante da concepção ordinária e das ciências aplicadas. Nenhum evento, tomado isoladamente, pode ser suficiente para outro evento, apenas um estado físico, compreendendo tudo que pode influenciar um evento, poderia ser suficiente para a ocorrência deste. Como, segundo a teoria da relatividade, a luz é a cadeia causal mais rápida, qualquer evento $e$ pode ser influenciado por eventos dentro do seu cone de luz passado. Estes eventos são tais que a sua distância no espaço-tempo ao evento e permite que um sinal luminoso o alcance.

Outro ponto, já sugerido no texto de Russell, é a importância dos sistemas isolados para as nossas atribuições causais. Resta avaliar até que ponto o exame destes sistemas subscreve as conclusões pessimistas de Russell sobre a noção de causa. Quando elaboramos um modelo causal para uma pedra muito pesada em queda livre, nós podemos considerar o sistema contendo a pedra e a Terra como praticamente isolado. Sabemos que as forças nuclear forte e nuclear fraca enfraquecem dramaticamente dentro de uma escala de distância do tamanho de um átomo. Embora a força eletromagnética tenha maior alcance, os corpos geralmente são eletricamente neutros ou com pouca carga elétrica. A gravitação então é a força dominante na maioria das interações entre corpos massivos. Nas nossas imediações, não existem variações significativas de massa e, portanto, podemos considerar a força gravitacional como fixa (ver Elga 2007, p.109). Nossas asserções causais são feitas dentro deste tipo de sistema. Até aqui, não avançamos muito para além do que Russell sabia.

Existem também sistemas que são sensíveis a influências distantes e de pequenas magnitudes. Por exemplo, sismógrafos, fotômetros, bússolas, etc. Estes artefatos reagem a influências muito específicas e são insensíveis a todas as outras influências. Nesta medida, tais artefatos podem ser tratados como sistemas isolados, já que estão ao abrigo de todas as influências, exceto aquela para a qual foram construídos.

Há outro tipo de situação, discutida em Elga (2007), que merece consideração. Consideremos um amplificador browniano, com uma partícula de poeira flutuando 
dentro de um cilindro de vidro selado. A posição da partícula é sensível a todos os tipos de influências distantes e de pequenas magnitudes. $\mathrm{O}$ amplificador faz um beep ou um whistle, conforme a partícula esteja do lado esquerdo ou direito do recipiente. À primeira vista, parece que não podemos tratar este sistema como isolado já que é muito sensível às mais diversas e longínquas influências. Lembremos, entretanto, que somos criaturas com limitações importantes em nossas capacidades de observação e controle, sendo extremamente improvável que consigamos manejar a condição $C$, extremamente complexa, que permitisse inferir que o próximo som seria um beep (alternativamente, um whistle). E, se nós não conseguimos descobrir esta condição, o melhor que podemos fazer é tratar o nosso aparato como sendo randômico e produzindo cerca de $50 \%$ de beeps e $50 \%$ de whistles.

O que esta pequena discussão sugere é que estes sistemas supersensíveis podem ser tratados como sistemas randômicos que têm uma tendência interna para exibir o comportamento descrito acima. Nesta medida, podem ser tratados como sistemas isolados que não dependem de fatores externos. Estes sistemas poderiam ser considerados, na prática, análogos ao constituído pelo decaimento radioativo de um átomo de urânio. A física informa que nenhum fator externo é responsável pelo decaimento de um átomo determinado de uma amostra de urânio, tendo este uma tendência intrínseca para decair com certa probabilidade. Assim, além dos sistemas praticamente isolados discutidos no exemplo de Russell do sistema solar, ${ }^{5}$ temos os sistemas sensíveis a um tipo específico de influência e isolado quanto ao resto e, finalmente, sistemas supersensíveis que podem ser considerados isolados por considerações estatísticas.

Tudo considerado, nos vários tipos de sistema isolados, a causalidade surge como produto de certos arranjos particulares e de fatos acerca das nossas leis. Depende, por exemplo, de como os sistemas estão distribuídos no espaço e no tempo e da natureza e alcance das forças descritas pelas leis da física. Ainda, as relações causais dependem das nossas limitações cognitivas (e como agentes) na medida em que descrevemos grosseiramente os eventos. O mais interessante, entretanto, é fato de existirem certas regularidades intrínsecas a um determinado sistema que são mais simples e manejáveis do que a totalidade das regularidades. Este fato não só permite que nossas limitações cognitivas não sejam um problema, mas habilita-nos a explorar vantajosamente certos padrões escritos, por assim dizer, em letras maiúsculas.

\section{Assimetria}

Uma tradição que remonta a Reichenbach e Boltzmann tem procurado solucionar um dos maiores enigmas sobre a constituição do mundo físico. Todas as leis físicas fundamentais para explicar os aspectos dinâmicos do mundo são temporalmente si-

Principia 16(3): 353-364 (2012). 
métricas. Isto quer dizer, numa formulação de Loewer que "se uma seqüência de eventos fundamentais é compatível com as leis dinâmicas, então há uma seqüência temporalmente invertida de eventos fundamentais que é também compatível com estas leis" (Loewer 2007). Sendo assim, as diversas noções que consideramos assimétricas no tempo, tais como causação, agência, radiação, dentre outras, permanecem altamente problemáticas dentro desta imagem física do mundo. Aqueles que tentam superar este impasse apelam quase invariavelmente a $2^{\text {a }}$ lei da termodinâmica. Grosso modo, a lei afirma que a entropia de sistemas isolados nunca (ou quase nunca) decresce. ${ }^{6}$

Para Reichenbach, sempre buscamos a fonte de coincidências improváveis em algum evento no passado - uma causa comum. Uma coincidência improvável é um estado de ordem dentro de um sistema quase isolado e este estado só pode ser produzido por interação com algo em um estado de maior ordem que, pela segunda lei, deve ocorrer no passado do sistema. Não é claro, entretanto, a partir da explicação de Reichenbach, como compreender a assimetria causal em todos os casos, por exemplo, naqueles em que não procuramos explicar coincidências improváveis.

Há uma intuição presente em vários autores, dentre eles, Lewis e Popper que pode ajudar. Lewis, em sua famosa teoria contrafactual da causação, diz, muito simplificadamente, que "c causa $e$ ", se e somente se, existe um mundo possível onde $c$ e $e$ não ocorreram que é mais próximo ao nosso mundo do qualquer mundo em que $e$ ocorreu sem $c$. Isto, entretanto não é a historia toda, pois existe o conhecido problema dos contrafactuais retrocedentes (backtracking counterfactuals). Se o mundo em que $e$ não ocorre e $c$ não ocorre fosse mais próximo ao nosso do que o mundo em que $e$ não ocorre mas $c$ ocorre, nós teríamos que $e$ causa $c$, invertendo a direção da influência causal. A solução de Lewis é a de invalidar o condicional retrocedente, afirmando que o mundo mais próximo ao nosso em que $e$ não ocorre é um mundo em que $c$ ocorre, mas que - por um milagre que suspende temporariamente uma lei falha em produzir e. A explicação de Lewis para tal é que, ao compararmos os mundos possíveis onde $e$ não ocorre, o mundo em que $c$ não ocorre é muito dissimilar ao nosso, pois as causas deixam inúmeros traços. Assim, aquele que, por exemplo, comete um assassinato disparando uma arma de fogo deixa inúmeros traços no mundo: pólvora na roupa, ondas sonoras e luminosas que se propagam pelo espaço, marcas no revólver, as várias pessoas que se assustam com o barulho e todas as outras diferenças introduzidas no mundo pelas quais os homicidas são descobertos. Esta é a tese lewisiana de que o futuro sobredetermina o passado. Mais precisamente, há muitos conjuntos de traços que são juntamente suficientes para um evento passado.

A famosa carta de Popper, ao editor da revista Nature, em 1956, oferece uma magnífica ilustração do ponto. Uma pedra é atirada em um lago e forma as características ondas concêntricas. O processo inverso, em que as ondas se contraem e expelem a pedra, nunca é observado. ${ }^{7}$ Popper observa que, para produzir o pro- 
cesso inverso, teríamos que colocar geradores coordenadamente ligados nas bordas do lago. Como podemos notar, a natureza conspiratória de tal coordenação torna improvável o seu caráter natural. O exemplo do lago é geralmente referido como representando a assimetria da radiação, sendo polêmica a sua assimilação à assimetria da entropia. Lewis diz que o exemplo de Popper é um caso particular da sobredeterminação do passado pelo futuro, mas que não sabe como conectar esta com considerações sobre entropia.

Em princípio, o que temos aqui é simplesmente uma estrutura analógica. A assimetria da sobredeterminação do passado pelo futuro (Lewis), a assimetria da radiação (Popper) e as assimetrias termodinâmicas podem ser pensadas conjuntamente tendo em vista a idéia de ação conspiratória. Começando pela termodinâmica, seria altamente improvável que um gás, espalhado em um container isolado, ocupe certo canto deste, pois suas moléculas teriam viajar em direções e sentidos coincidentes. Nós só admitiríamos isto se houvesse algum dispositivo externo para induzir este comportamento e, neste caso, o sistema não estaria isolado do resto do universo. Da mesma forma, no exemplo do assassinato, esperaríamos que no mundo $w_{2}$, onde a pessoa da vítima não morreu $(\sim e)$ e o potencial assassino não atirou $(\sim c)$, teríamos que imaginar algum tipo de conspiração para forjar todos os traços que o tiro introduz no mundo $w_{0}$ (o mundo atual). A analogia parece perfeita, mas é insuficiente como uma resposta cabal a Russell, pois precisaríamos saber como reduzir a assimetria da sobredeterminação à assimetria termodinâmica.

Várias tentativas têm sido feitas para explicar a ligação demandada acima. Particularmente interessante, é a explicação de David Kutach. A idéia geral é que no nível microscópico há alguma dependência do passado em relação ao presente. Se o presente tivesse sido diferente, certos detalhes microscópicos do passado seriam diferentes. No nível macroscópico, entretanto, não há tal dependência. Pensando a influência causal indo em direção ao passado, se alterássemos detalhes microscópicos que evitariam a morte da pessoa do nosso exemplo (evento macroscópico), nós alteraríamos detalhes microscópicos do passado, mas seria improvável que estas alterações se propagassem para o passado e se cristalizassem no evento macroscópico consistindo da desistência do intento assassino $(\sim c)$. Particularmente, parece excepcionalmente improvável que tais mudanças microscópicas se avizinhassem da região espacial onde a pessoa do assassino se encontrava levando a alguma alteração compatível com $(\sim c)$. Eu entendo que algo desta explicação, embora mais sofisticada, é o que podemos encontrar em Kutch 2007).

\section{A realidade da causação}

A discussão acima leva a questão metafísica da realidade da causação. Em todos os casos que discutimos, como os sistemas praticamente isolados e os sistemas super-

Principia 16(3): 353-364 (2012). 
sensíveis, parece que causação é simplesmente um procedimento útil de inferência para as ciências especiais e para os contextos ordinários. Ela aparece como um procedimento de simplificação dentro de sistemas com características especiais, não sendo fundada por leis fundamentais apenas. Causação seria um estranho e surpreendente benefício do conhecimento incompleto. Outra maneira de pensar é evitar entender as leis fundamentais da física como a única medida do que existe e tentar mostrar que aspectos não-nômicos do mundo físico contribuam para a ossatura da causação. Neste sentido, Woodward, por exemplo, diz:

\begin{abstract}
[...] asserções causais macroscópicas (semelhantemente a chances em mundos determinísticos) refletem verdades complicadas acerca de (i) a realidade microfísica subjacente e (ii) a relação de agentes macroscópicos para objetos deste mundo. Este segundo ingrediente dá as asserções causais macroscópicas certo número de características — granularidade grosseira, foco sobre mundos pequenos, que permitem a possibilidade de intervenções de fora, confiança em fatos contingentes acerca de condições iniciais e de contorno e assim por diante - mas isto não faz tais asserções 'subjetivas' no sentido de não serem controladas por evidência, dependentes de gostos idiossincráticos ou interesses de investigadores individuais e assim por diante (Woodward 2007, p.102).
\end{abstract}

Falta ainda, na literatura atual, um detalhamento convincente de como as verdades complicadas sobre o mundo microscópico e macroscópico, de que fala Woodward, se combinam para produzir o tipo de simplificação necessário para as asserções causais.

\title{
6. Conclusão
}

Neste ponto, devemos avaliar as críticas russellianas naquilo que elas ainda fazem sentido para nós. Como já dissemos, as associações enganadoras da palavra 'causa' podem ser resolvidas com alguma discussão preliminar que diminua a polissemia do termo. Uma preocupação maior é a que a noção de causa, uma vez depurada, possa ainda ser incoerente, na medida em que abriga elementos irreconciliáveis. Por exemplo, se pensamos que as causas são suficientes para os seus efeitos, uma causa seria algo estranhamente distante de seu emprego nos afazeres cotidianos e nas ciências particulares. Apenas um estado físico detalhadamente descrito, cobrindo uma parte considerável do espaço-tempo, poderia ser suficiente para certa ocorrência. Eu não creio realmente que a idéia de causa como condição suficiente, quando estamos pensando em eventos grosseiramente descritos, seja parte de nosso conceito de causação. Talvez, a idéia de suficiente nas circunstâncias seja o que temos em mente, quando falamos da causa como sendo suficiente. Portanto, não é claro que haja realmente características conflituosas em nossa noção de causalidade.

Principia 16(3): 353-364 (2012). 
O ponto mais substancial da crítica de Russell, com mais eco na literatura atual, é o de que causas não existem. Aqui, alternativamente, podemos dizer pura e simplesmente que causas existem ou ainda assumir uma posição intermediária - causas existem secundariamente. A última opção me parece mais interessante, já que, pela discussão acima, temos um forte indício de que nossas asserções causais possuem uma base física, embora não possam ser explicadas diretamente através da ontologia da física envolvendo apenas as leis fundamentais. Se considerarmos que o mundo é um vasto padrão de regularidades e matérias de fato, veremos que neste padrão aparecem subpadrões que não podem ser considerados meramente subjetivos ou ficcionais. A realidade da causação pertence a estes subpadrões. Russell está substancialmente certo ao pensar que a causalidade não pode explicar a física fundamental, mas investigar em que medida a física pode explicar a causalidade é ainda um programa valioso.

\section{Referências}

Cartwright, N. 1983. Causal Laws and Effective Strategies. In: Cartwright, N. How the Laws of Physics Lie. Oxford: Oxford University Press, 1983, p.21-43.

Elga, A. 2007. Isolation and Folk Physics. In Price \& Corry 2007, p.106-19.

Field, H. 2004. Causation in a Physical World. www.nyu.edu/gsas/dept/philo/faculty/field. Acessado em novembro de 2004.

Hitchcock, C. 2007. What Russell Got Right. In Price \& Corry 2007, p.55-65.

Kutach, D. 2007. The Physical Foundations of Causation. In Price \& Corry 2007.

Lewis, D. 1991. Counterfactual Dependence and the Time's Arrow. In Jackson, F. (ed.) Conditionals. Oxford: Oxford University Press, 1991.

— 1997. Causation. In Sosa, E. \& Tooley (eds.) Causation. Oxford: Oxford University Press, 1997.

Loewer, B. 2007. Counterfactual and the Second Law. In Price \& Corry 2007p. 293-326.

Popper, K. 1956. The Arrow of Time. Nature 177: 2.

Price, H. 1996. Time's Arrow and Archimedes' Point: new directions for the physics of time. Oxford: Oxford University Press.

Price, H.; Corry, R. (orgs.) 2007. Causation, Physics, and the Constitution of Reality - Russell's republic revisited. Oxford: Clarendon Press.

Reichenbach, H. 1999. The Direction of Time. Mineola: Dover Publications.

Russell, B. 1917. On the Notion of Cause. In: Mysticism and Logic and other Essays. London: George Allen \& Unwin Ltd.

Woodward, J. 2007. Causation with a Human Face. In Price \& Corry 2007, p.66-105.

TÚlio Roberto Xavier de Aguiar Departamento de Filosofia UFMG Av. Antônio Carlos, 6627 Campus Pampulha 31270-901 Belo Horizonte, MG

Principia 16(3): 353-364 (2012). 
BRASIL

taguiar.bh@terra.com.br

Resumo. Nesse trabalho, pretendo analisar o nosso conceito de causa em face da crítica de Bertrand Russell em seu artigo "On the Notion of Cause". Para Russell, há um estranhamento entre a noção de causa e a ciência madura da física. A palavra causa (e seus correlatos) não seria utilizada na física, retirando assim a principal justificativa da filosofia para o seu emprego - a fundamentação da ciência. Assim, as diversas noções causais e o princípio de causalidade deveriam ser abandonados pelos filósofos como algo ultrapassado. O objetivo desse trabalho é avaliar em que medida a nossa noção de causa, com seu caráter assimétrico, pode ser explicada pela física e investigar a questão da existência das causas em nosso mundo.

Palavras-chave: Leis; causa; assimetria; sistemas isolados; Russell.

\section{Notes}

${ }^{1}$ Russell diz "a lei", pois no trecho anterior formula um substituto físico para o principio clássico de causalidade. Este princípio fala de taxas de variação de mudanças que ocorrem em nosso universo. Tal princípio é uma paráfrase das equações diferenciais da mecânica newtoniana. Há um forte consenso sobre a simetria das demais leis da física.

2 Para evitar a intrusão de expressões antropomórficas, tais como "produção", "levar a", "fazer ocorrer" e assim por diante, devemos utilizar formulações contrafactuais para ligar o passado e o futuro. Assim, podemos ver que, em um mundo determinístico, se o futuro fosse diferente, o passado seria diferente e não descobrimos aí qualquer assimetria.

${ }^{3}$ A experiência de pensamento de Russell é complicada pelo fato de que é difícil avaliar como o universo seria no caso da força da gravidade ser proporcional à distância. Neste caso, será que teríamos planetas e estrelas? É difícil de dizer, mas de qualquer forma o ponto da lição que Russell quer extrair permanece o mesmo. As atribuições causais dependem do tipo de leis e do tipo de universo em que vivemos.

${ }^{4}$ Não precisamos restringir as relações causais a uma ligação entre eventos, podemos também aceitar fatos ou valores de variáveis como relata da causação. Isto não afeta o ponto do texto, já que o argumento de Russell não parece depender especialmente da ontologia da causação.

${ }^{5}$ Russell faz ainda outra precisão relativa à noção de sistema isolado. Devemos especificar relativamente a qual fenômeno o isolamento se dá. Ele diz: "estritamente falando, nós devemos especificar em que respeito o sistema é relativamente isolado. Por exemplo, a Terra é relativamente isolada com respeito aos corpos em queda, mas não com relação as marés; é praticamente isolada com relação aos fenômenos econômicos, embora, se a teoria da relação entre as manchas solares e as crises econômicas de Jevons fosse verdadeira, ela não teria sido praticamente isolada em relação àqueles fenômenos" (Russell 1913, p.198).

${ }^{6}$ Não parece que a $2^{\text {a }}$ lei da termodinâmica seja em si mesma assimétrica. O que a lei diz realmente é que um sistema tende a alcançar o equilíbrio, a máxima entropia. Em nosso universo, isto significa o aumento da entropia porque havia baixa entropia em sua origem. A assimetria da entropia está realmente nas condições iniciais do nosso universo.

Principia 16(3): 353-364 (2012). 
${ }^{7}$ Lewis diz: "countless tiny samples of the wave each determine what happens at the spacetime point where the wave is emitted or absorbed. The processes that occur are the ones in which this extreme overdetermination goes toward the past, not those in which it goes toward the future. I suggest that the same is true more generally" (Lewis 1991, p.67).

Principia 16(3): 353-364 (2012). 